\title{
Food Choice Drivers in the Context of the Nutrition Transition in Delhi, India
}

\author{
Claire Bailey, MPH, RD ${ }^{1}$; Vandana Garg, $\mathrm{MSc}^{2}$; Deksha Kapoor, $\mathrm{MSc}^{2}$; \\ Heather Wasser, PhD, MPH, RD ${ }^{1}$; Dorairaj Prabhakaran, MD, DM, MSc²; \\ Lindsay M. Jaacks, $\mathrm{PhD}^{3}$
}

\begin{abstract}
Objective: To understand factors that influence the process of food decision-making among urban Indian women in the context of the nutrition transition.

Design: Mixed methods.

Methods: Semistructured interviews and sorting of 12 a priori hypothesized drivers into categories of always, sometimes, and never influencing food choice.

Setting: Delhi, India.

Participants: Thirty-eight women aged 20-35 years selected from the roster of a prospective cohort study. Phenomenon of Interest: Drivers of food choice.

Analysis: Interviews were transcribed verbatim and translated, then analyzed using an iterative, constant comparative process. Differences in pile sort rankings across tertiles of body mass index and wealth index were tested using Fisher exact tests.

Result: Four primary themes emerged: (1) family influence; (2) cultural perceptions, with 3 subthemes of beliefs relating to (a) outside food and less healthful food, (b) seasonality, and (c) hometown food; (3) convenience, with 3 subthemes of (a) decisions regarding procurement of food, (b) not having time to cook, resulting in eating out or purchasing premade foods, and (c) eating whatever is available at home or is left over from previous meals; and (4) habit, with 2 subthemes of (a) subconscious decisions and (b) food roots. Responses from the pile sort activity revealed perceptions that food safety and health most influence food choice whereas marketing and advertisements least influence it.

Conclusions and Implications: Young adult women in Delhi seem to rely on preferences of their families, habits and perceptions established in childhood, convenience, and food safety and health when making choices about food. These aspects of decision-making should be targeted in future interventions aimed at improving dietary intake in this population.

Key Words: India, Diet, food preferences, mixed methods, urban health (J Nutr Educ Behav. 2018;50:675-686.)
\end{abstract}

Accepted March 29, 2018. Published online April 27, 2018.

\footnotetext{
${ }^{1}$ Department of Nutrition, University of North Carolina at Chapel Hill Gillings School of Global Public Health, Chapel Hill, NC

${ }^{2}$ Public Health Foundation of India and Centre for Chronic Disease Control, Gurgaon, Haryana, India

${ }^{3}$ Department of Global Health and Population, Harvard T.H. Chan School of Public Health, Harvard University, Boston, MA

Conflict of Interest Disclosure: The authors have not stated any conflicts of interest.

Address for correspondence: Lindsay M. Jaacks, PhD, Department of Global Health and Population, Harvard T.H. Chan School of Public Health, Harvard University, Bldg 1, Rm 1211, 665 Huntington Ave, Boston, MA 02115; Phone: (617) 432-2505; Fax: (617) 432-6133; E-mail: jaacks@hsph.harvard.edu

(C) 2018 Society for Nutrition Education and Behavior. Published by Elsevier, Inc. All rights reserved.

https://doi.org/10.1016/j.jneb.2018.03.013
}

\section{INTRODUCTION}

As household spending power has increased in India, dietary intake has shifted in a process called the nutrition transition ${ }^{1}$ : consumption of energy-dense, processed foods such as fried and salted snacks and prepared sweets is increasing. Moreover, although carbohydrates still account for a large proportion of total energy intake (73\% in rural areas and 68\% in urban areas ${ }^{2}$ ), coarse grains (wholewheat flour, brown rice, millet, barley, and sorghum) are being replaced with refined grains (white flour and polished white rice). ${ }^{3}$ However, distinct from the nutrition transitions characterized in China, ${ }^{4}$ Mexico, ${ }^{5}$ and Brazil, ${ }^{5}$ the intake of meat and 
sugar-sweetened beverages has not risen dramatically in India. ${ }^{6}$

Traditional diets in India vary considerably across regions, with whole wheat-based breads (eg, chapatis or roti) contributing a majority of calories in the north and rice and lentils (including dosa [rice-lentil crepe] and idli [steamed rice-lentil cake]) being the major contributors in the south. Traditionally, dairy products, with the exception of yogurt, are more common in the north $(\mathrm{eg}, \mathrm{milk}$, ghee [clarified butter], and paneer [cheese]) and coconut is more common in the south. A meal typically consists of a staple grain with seasonal vegetables (depending on the recipe, the cooking method could be shallow or deep frying) and sometimes a pulse/lentilbased dish (pressure-cooked).

The nutrition transition in India has been accompanied by an epidemiological transition, particularly in urban areas. A recent analysis by the India State-level Disease Burden Initiative found that in 2016, noncommunicable diseases (NCDs) such as cardiovascular disease, diabetes, and cancer accounted for $61.8 \%$ of deaths compared with undernutrition and communicable, maternal, and neonatal diseases, which together accounted for just $27.5 \%$ of deaths. ${ }^{7}$ They also found that in 1990, Delhi, which is located in the northern part of India, was among the first areas in India to experience the epidemiological transition; it had more deaths attributable to NCDs than undernutrition and communicable, maternal, and neonatal diseases at that time. ${ }^{7}$ Delhi, which is the nation's capital and second largest city (the population according to the 2011 Census was approximately 11 million), is also uniquely diverse in its food culture, although heavily influenced by traditional northern Indian cuisines. Given this evidence of a substantial and increasing burden of NCDs in India, and Delhi specifically, interventions targeting key risk factors for NCDs, such as dietary intake, are urgently needed. ${ }^{8}$

To develop such interventions, a greater understanding of underlying drivers of dietary behaviors in India is needed. As outlined by the Food Choice Process Model, decisions relating to food choice are frequent, complex, and multifaceted, and vary over both personal and historical time. ${ }^{9,10}$ Research conducted in highincome countries found that cultural ideals are among the most important drivers of food choice, as are personal factors such as taste preference and identities. ${ }^{10}$ Only 1 previous study explored drivers of food choice in the context of India. That study, which was conducted in rural Kerala, the southernmost state of India, found that food choices within the household were strongly influenced by the preferences of husbands and children, as well as cost. ${ }^{11}$ Given that Indian women are the primary cooks in the household ${ }^{11}$ and that they are more likely to be overweight or obese compared with men, ${ }^{12}$ the 2 objectives of this study were (1) to determine the drivers of food choice among young adult women living in Delhi and (2) to interpret these drivers in the context of the nutrition and epidemiological transitions.

\section{METHODS}

\section{Participants and Recruitment}

The researchers used a combination of semistructured and structured quali-
Table 1. Distribution for Sample Selection of Women Aged 20-35 Y $(n=38)$ Wealth Index (Tertile)

\begin{tabular}{llll} 
Body Mass Index, $\mathbf{k g} / \mathbf{m}^{2}$ & $\mathbf{1}$ & $\mathbf{2}$ & $\mathbf{3}$ \\
$18.5-24.9$ & 6 & 6 & 6 \\
$\geq 25$ & 6 & 6 & 8 \\
\hline
\end{tabular}

Note: Data are shown as $\mathrm{n}$. Wealth index was derived using principal component analysis based on household amenities (separate cooking room and toilet facilities) and assets (television, refrigerator, washing machine, microwave, mixergrinder, mobile phone, DVD player, computer, car, motorized bike, and bicycle). tative methods to identify drivers of food choice among women aged 2035 years living in Delhi. A total of 38 women were purposively selected from the roster of a prospective cohort study called the Centre for Cardiometabolic Risk Reduction in South Asia (CARRS) Surveillance Study. ${ }^{13}$ The CARRS study used multistage probability sampling to select a representative sample of Delhi at baseline, in 2014, and has continued to follow up with participants annually to collect data on incident disease. To be eligible for inclusion in the CARRS study, individuals had to be living in Delhi for $\geq 5$ years with no plans to move from Delhi in the next 5 years.

For the purposes of this mixedmethods study, 2 categories of body mass index (BMI) and tertiles of household wealth index were calculated using the CARRS dataset for women age 20-35 years. Body mass index was derived as weight (in kilograms) divided by height squared (in meters) using measured values of weight and height obtained by trained field staff. Wealth index was derived using principal component analysis based on household amenities (separate cooking room and toilet facilities) and assets (television, refrigerator, washing machine, microwave, mixer-grinder, mobile phone, DVD player, computer, car, motorized bike, and bicycle). ${ }^{14}$ Women were enrolled from each category of BMI-by-wealth index (Table 1).

Sociodemographic characteristics including age, educational attainment, employment status, household size, monthly household income, and religion were also obtained from the CARRS dataset. The CARRS survey questions were derived from questionnaires used in the Chennai Urban Population Study, the Chennai Urban Rural Epidemiological Study, and the Sentinel Surveillance Study, ${ }^{13}$ and all surveys were administered in person by trained field staff.

This study was approved by the Institutional Review Boards of the University of North Carolina at Chapel Hill and Harvard University, and the Centre for Chronic Disease Control Ethics Committee. Written informed consent was obtained from all participants. Participants were not compensated for their participation. 


\section{Semistructured Interviews}

The interview guide (Supplementary Data) was adapted from a previous study on drivers of food choice among women and men residing in Kerala, India, ${ }^{11}$ as well as informed by the Food Choice Process Model. ${ }^{9,10}$ The initial interview script was pilottested with 3 young adult women. The initial interview guide asked only about health perceptions of the foods mentioned by participants in the dietary recall. After the pilot interviews, the guide was revised to probe more generally about perceptions of healthy and unhealthy foods. Questions about whom the participant sought for dietary advice and how the participant's eating habits had changed since youth were also added to the guide after pilot interviews. Finally, some questions were revised to be more open-ended, and more detailed probes were added as subquestions under each main question to ensure the interviews resulted in rich data.

Analysis of these pilot interviews identified key issues and concepts that were used to revise the interview guide before use in the field. Each field interview was conducted in the home of the participant and lasted 20-40 minutes. With the permission of the participant, all interviews were audiorecorded. Interviews were conducted between September and November, 2016 by nutritionists trained in qualitative methods (DK and VG) in the participant's native language (Hindi), with the exception of 1 interview conducted by CB in English. Audio recordings were transcribed verbatim and translated into English by a hired, trained translator and English transcripts were verified by DK and VG.

Each interview began with a standard dietary recall (except that the amount of intake was not obtained) to elicit information about the types of foods and beverages consumed by participants in the previous 24 hours. The core of each interview consisted of open-ended questions about why the participant decided to consume each food or beverage mentioned during the recall and whether the food or beverage was typical of the participant's usual diet. After the pilot tests, more specific prompts about cost, physical environment, health, family members, and media were added to the guide. Further questions attempted to discern whether the participant's current diet was similar to or different from her diet during childhood, and whether her current diet was similar to or different from her parents' diets when they were her age. Asking these specific questions deepened the understanding of her food choices in the context of the nutrition and epidemiological transitions.

\section{Pile Sorts}

At the end of the interview, participants were asked to complete a pile sort activity in which they classified 12 a priori hypothesized drivers of food choice based on the previously mentioned study in Kerala, India, ${ }^{11}$ as well as the Food Choice Process Model, ,,10 into categories of always influences food choice, sometimes influences food choice, and never influences food choice. The 12 drivers in the pile sort activity were as follows: hunger/appetite, taste, cost of food/income, time available, mood, knowledge about food, cooking skills, health, food safety, packaging/labeling, marketing/advertisements, and attitudes/beliefs about certain foods (including cultural beliefs/traditions). The initial pile sorting activity asked participants to rank the 12 drivers in terms of how much influence each driver had on their food choice relative to the other drivers. However, after pilot-testing, it became clear that this was too challenging for participants, so the pile sorting activity was revised to ask participants to sort the 12 drivers into the 3 categories of always, sometimes, or never.

\section{Data Analysis}

The researchers conducted analysis of the qualitative data using Dedoose (version 7.0.23, SocioCultural Research Consultants, LLC, Los Angeles, CA, 2016). The research team members read and reviewed transcripts individually, followed by a group meeting to discuss emergent codes, categories, concepts, and themes. The first review and meeting occurred after the transcription of the 3 pilot interviews to ensure the quality of the data and allow for any necessary adjustments to the interview guide. An initial codebook was created with codes borrowed from a study on food choices by Furst et al. ${ }^{10}$

After this first meeting and the development of an initial codebook by $\mathrm{CB}, \mathrm{LMJ}, \mathrm{HW}, \mathrm{VG}$, and $\mathrm{DK}, \mathrm{CB}$ individually coded subsequent transcripts, followed by additional meetings and adjustment of the interview guide and codebook as needed. Inductive codes were added to the initial codebook as additional concepts emerged from the interview transcripts. To improve reproducibility, all codes were clearly defined and mutually exclusive. Following Campbell et al, ${ }_{15}^{15} 2$ types of reliability were assessed: stability and reproducibility (eg, intercoder reliability and agreement). Stability, or whether a coder's use of codes changes over time, ${ }^{15}$ was addressed by LMJ, who reviewed all coded transcripts for consistency. Reproducibility was addressed by VG and DK, who independently coded $20 \%$ of transcripts. Of the 244 excerpts in CB's coded transcripts, 38 had a discrepant code compared with VG and DK's coded transcripts (85\% agreement). After discussions by CB, LMJ, VG, and $\mathrm{DK}$, all discrepancies were reconciled. Coding reports were exported from Dedoose and analyzed using a constant comparative method ${ }^{16,17}$ by $\mathrm{CB}$ and LMJ. Original categories arising from the interviews were applied to the cumulative data and revised multiple times until there was group consensus about their fit.

Analysis of the pile sort activity was conducted using SAS (version 9.4, SAS Institute, Cary, NC, 2013). Differences in pile sort rankings (always, sometimes, or never) across tertiles of BMI and wealth index were tested using Fisher exact tests. $P<.05$ was considered statistically significant.

\section{RESULTS}

The mean age of participants was 29.5 years and most were homemakers (Table 2). Four primary themes emerged: (1) family influence, (2) cultural perceptions, (3) convenience, and (4) habits (Figure 1). These are each discussed in detail in subsequent text, followed by results of the structured technique (pile sorts). 
Table 2. Demographic Characteristics of Study Participants $(n=38)$

\begin{tabular}{|c|c|}
\hline Characteristics & $\%(n)$ \\
\hline Age, y (mean [SD]) & $29.5(4.3)$ \\
\hline \multicolumn{2}{|l|}{ Highest education level attained } \\
\hline Illiterate & $3(1)$ \\
\hline Literate, no formal education & $5(2)$ \\
\hline Primary school & $3(1)$ \\
\hline High school & $21(8)$ \\
\hline Secondary school & $26(10)$ \\
\hline University graduate & $32(12)$ \\
\hline Professional degree/postgraduate & $11(4)$ \\
\hline \multicolumn{2}{|l|}{ Employment status } \\
\hline Housewife & $84(32)$ \\
\hline Employed & $13(5)$ \\
\hline Student & $3(1)$ \\
\hline \multicolumn{2}{|l|}{ Household size (mean [SD]) } \\
\hline Adults (age $\geq 18$ y) & $2.8(1.1)$ \\
\hline Children (age < 18 y) & $1.8(1.0)$ \\
\hline \multicolumn{2}{|c|}{ Estimated total household income/mo (INR) } \\
\hline $3,000-10,000$ & $24(9)$ \\
\hline $10,001-20,000$ & $40(15)$ \\
\hline $20,001-30,000$ & $18(7)$ \\
\hline $30,001-40,000$ & $3(1)$ \\
\hline $40,001-50,000$ & $8(3)$ \\
\hline$>50,000$ & $5(2)$ \\
\hline Do not know & $3(1)$ \\
\hline \multicolumn{2}{|l|}{ Religion } \\
\hline Hindu & $95(36)$ \\
\hline Muslim & $3(1)$ \\
\hline Christian & $3(1)$ \\
\hline
\end{tabular}

INR indicates Indian rupee.

Note: Demographic data were collected as part of the Cardiometabolic Risk Reduction in South Asia Surveillance Study. ${ }^{13}$

\section{Family Influence}

For nearly all women interviewed, husbands, children, and in-laws were a primary driver of food choice. Mothers-in-law influenced decisions about food procurement (Table 3). Children and husbands were especially influential regarding decisions related to eating away from home. This influence often led to unhealthy food decisions:
Sometimes [I have a snack] when children bring something like samosa [deep-fried refined wheat Indian snack stuffed with potato and peas] and like chow mein [noodles] (age 27, $23.3 \mathrm{~kg} / \mathrm{m}^{2}$, wealth tertile 1 ).

It was evident that women prioritized the preferences of their husband and children over their own preferences; for example, "I try to serve everything for my family, whatever they like to have. I don't get time for myself" (age 33, BMI $29.0 \mathrm{~kg} / \mathrm{m}^{2}$, wealth tertile 3 ), and "Time is always available [to cook] for children" (age 29 , BMI $22.6 \mathrm{~kg} / \mathrm{m}^{2}$, wealth tertile 2).

Many women identified their marriage, which in some cases involved moving to Delhi from their hometown, as a major life transition related to food choice. There were several instances in which the husband's food patterns took precedence over the woman's food roots, which was sometimes a barrier to making healthier food choices (Table 3).

\section{Cultural Perceptions}

Three key subthemes related to cultural perceptions: beliefs relating to (1) outside food and less healthful food, (2) seasonality, and (3) hometown food.

Beliefs relating to outside food and junk food. Although decisions about eating outside food were complex, there was a common underlying perception that outside food was unclean (Table 3 ). Many women perceived homemade food to be healthy regardless of nutritional content, simply because it was prepared at home. One participant summarized this idea: "Homemade food is healthy and outside junk is not" (age 34, BMI $28.5 \mathrm{~kg} / \mathrm{m}^{2}$, wealth tertile 3). However, there were exceptions in which women expressed a clear knowledge of nutrition: When explicitly asked about healthy and unhealthy foods, a large number of women recognized that oily and fried foods were unhealthy, as supported by the following quotation: "Less oily and less fried, because if we eat more oily, then it will affect our health and I will become fat, too" (age 28, BMI $24.8 \mathrm{~kg} / \mathrm{m}^{2}$, wealth tertile 1 ).

The term junk food was applied by several women to refer to Western foods such as pizza and burgers, and Indian snacks purchased from street vendors such as samosas and momos (dumplings) (Table 3). Packaged foods such as biscuits (main ingredients were refined wheat, sugar, and butter), which were almost always consumed with tea, were never referred to as junk food. In fact, most women felt that tea must be taken with biscuits: "I am used 
to taking a cup of tea with 1 or 2 biscuits. I can't have empty tea. Only tea causes acidity, so I always take a biscuit" (age 26, BMI $22.3 \mathrm{~kg} / \mathrm{m}^{2}$, wealth tertile 3 ).

Beliefs relating to seasonality. Seasonality had an important role in food choices, particularly as related to beverages and fruits. Cultural perceptions relating to seasonality regarding beverages were a strong driver, in some cases even stronger than taste preference (Table 3). With respect to fruits, cost and seasonality interacted in driving food decisions; for example, "We don't have fruits daily, we don't get too much salary, but we try to have seasonal fruits once in week" (age 35, BMI $30.6 \mathrm{~kg} / \mathrm{m}^{2}$, wealth tertile 1 ), and "... seasonal fruits are cost friendly" (age 27, BMI $31.2 \mathrm{~kg} / \mathrm{m}^{2}$, wealth tertile 3 ).

Beliefs relating to hometown food. There was also a common perception that food from the woman's hometown was better in terms of both quality and taste, as demonstrated by the following quotation:

From my village to Delhi, it's a drastic change. Here we have less milk and other items, here everyone is keen to eat outside food. I was healthier when I was in my village as compared to Delhi (age 28, BMI $23.5 \mathrm{~kg} / \mathrm{m}^{2}$, wealth tertile 2)

There were some exceptions to this. For example, 1 woman said,

In the village, vegetables are not easily available, so we used to eat chapati with buttermilk and chutney, but here in Delhi I started eating vegetables more often because it's easily available (age 30, BMI $27.4 \mathrm{~kg} / \mathrm{m}^{2}$, wealth tertile 1 ).

\section{Convenience}

Excerpts from the theme of convenience could be classified into 3 subthemes: (1) decisions regarding procurement of food, (2) not having time to cook, resulting in eating out or purchasing premade foods, and (3) eating whatever is available at home or is left over from previous meals.

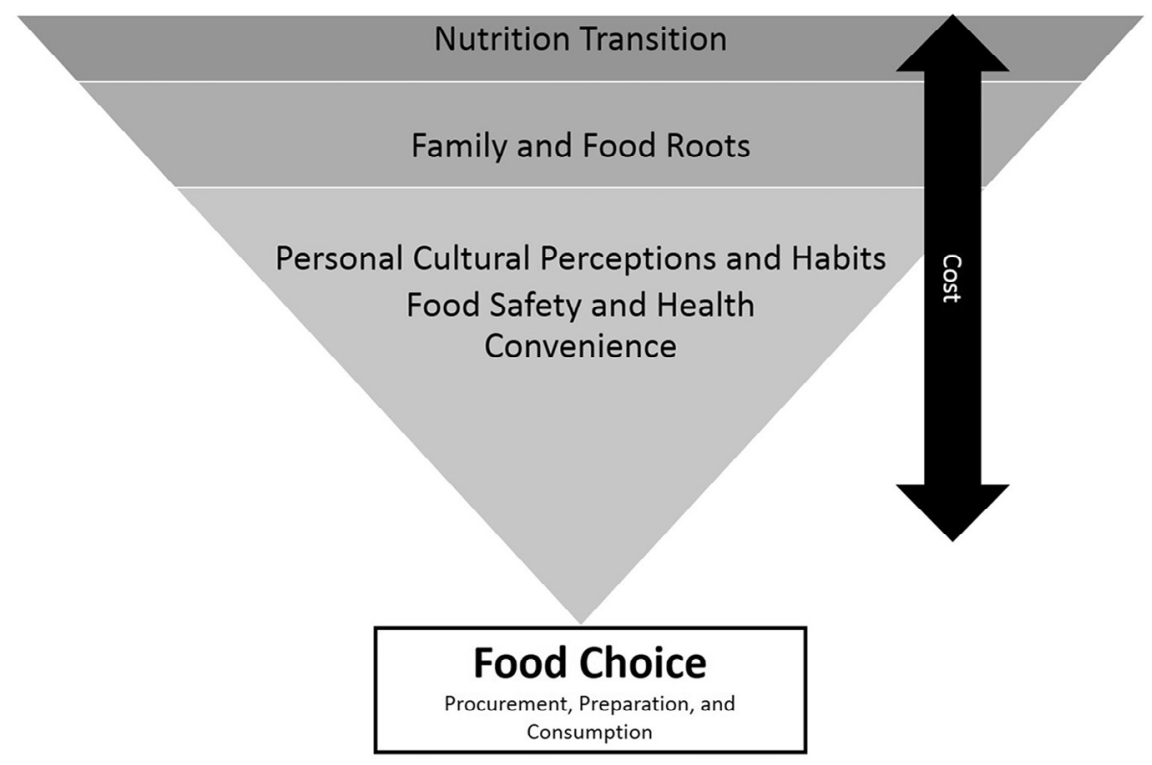

Figure 1. Conceptual framework of drivers of food choice among young adult women in Delhi, India.

Decisions regarding procurement of food. Convenience was especially important in the context of procuring food (Table 3). For some women, there was an interplay between time and cost, especially for nonperishable foods; for example,

\section{I prefer to buy all the dry food items once in month ... it's time and money saving. As often, there are offers on food items. So, we pur- chase in bulk for the whole month (age 26, BMI $22.3 \mathrm{~kg} / \mathrm{m}^{2}$, wealth tertile 3)}

and “... It [Big Bazaar Outlet] is near to my home. It's affordable when we buy in bulk" (age 28, BMI $24.8 \mathrm{~kg} / \mathrm{m}^{2}$, wealth tertile 1 ). The close proximity of a store also had a large role in where women decided to procure their food, especially with respect to fruits and vegetables. One participant, when asked why she bought vegetables only from the nearby shop, explained, "It saves my time because it is near our home ... because it's near and I don't have much time to go far to buy all these" (age 32, BMI $22.6 \mathrm{~kg} / \mathrm{m}^{2}$, wealth tertile 2).

Not having time to cook, resulting in eating out or purchasing premade foods. Several women found that eating outside food was convenient when they did not have time to cook, particularly for those in the highest wealth tertile and the few women in this sample who were employed. Three of these women explicitly said that they cooked less variety owing to their work schedules (Table 3). Several women who were homemakers also commented that they did not have time to eat owing to chores and sometimes delayed or skipped meals. The dominance of quotations from women in the highest wealth tertile suggests that a higher wealth index allows families to prioritize convenience rather than devoting time to meal preparation. There were some exceptions, with women still refusing to eat outside food despite time pressures: "We always have the time. Basically, for eating we always have the time" (age 32 , BMI $25.7 \mathrm{~kg} / \mathrm{m}^{2}$, wealth tertile 3). Not having time to cook was also mentioned in discussions of festival foods among women in the highest wealth tertile (Table 3).

Eating whatever is available at home or is left over from previous meals. This subtheme was particularly expressed among women from the lowest and middle wealth tertiles. When prompted to recall what she ate on the previous day, 1 participant stated, "I ate the same food which I cooked in the morning again at 2 in the 
Table 3. Direct Comparison of Food Choice Process Model and Constructs From Conceptual Framework of Drivers of Food Choice Among Young Adult Women in Delhi, India, as Well as Representative Quotations From Study Participants

\section{Food Choice Process Model Construct ${ }^{9}$ \\ Delhi Model Construct}

$\begin{array}{cc}\text { Contexts } & \text { Nutrition } \\ \text { transition }\end{array}$
transition

Social factors Family

Trajectories and transitions

Ideals

\section{Personal cultural perceptions}

\section{Quotation}

Earlier, my mother-in-law or my mother used to prepare gulab jamun [Indian sweet, a deepfried cottage cheese ball that is boiled in sugar syrup], sweet mathri [a deep-fried refined wheat snack], and salty mathri, sweet and savory snacks. But I don't have time, and also, all the items are easily available in the market.

People nowadays are working. They don't have time to cook a variety of food, so they prefer to cook less and purchase that from markets.

My mother-in-law, because she gets the entire stuff for home, like spices and all. My mother-inlaw gets all that.

Now, my husband likes food from outside, so I also started eating outside food.

I [ate] meat and egg more often in Bihar because my family members were not vegetarian, and here my husband is a pure vegetarian, so I eat meat and egg less often here in Delhi.

Earlier, I used to eat much less spicy and oily food. Now I eat more spicy and oily food ... Earlier, I didn't eat non-veg. Now, I started eating non-veg after marriage.

... We do not eat green vegetables now. My husband does not like to eat.

I eat rice at night and I want to change it but can't, because my husband wants rice at night daily, and I don't want to cook separate food for myself.

Yes, there is a change after marriage, as here, we use a lot of oil for cooking.

Home food is the best. Everything is cooked with clean hands. You see the way it is cooked outside! It seems so unhygienic.

All the junk food like Maggi [prepackaged noodles], burger, and pizza is unhealthy.

I like chow mein, so sometimes I have this, but I don't like momos, pizza, and other junk food.

Lemonade is also good for children, not in winter, but it is good in summer.

I like tea but not coffee and cold drinks. ... I cannot have anything cold in winter.

In UP [Uttar Pradesh], things were a lot purer... The oil is not pure here, the vegetable quality is poor. Even the spices are not sold whole but grinded only.
Participant Characteristics

Age 26, BMI $22.3 \mathrm{~kg} / \mathrm{m}^{2}$, wealth tertile 3

Age 30, BMI $24.9 \mathrm{~kg} / \mathrm{m}^{2}$, wealth tertile 2

Age 28, BMI $24.9 \mathrm{~kg} / \mathrm{m}^{2}$, wealth tertile 3

Age 20, BMI $21.2 \mathrm{~kg} / \mathrm{m}^{2}$, wealth tertile 1

Age 33, BMI $29.0 \mathrm{~kg} / \mathrm{m}^{2}$, wealth tertile 3

Age 26, BMI $22.3 \mathrm{~kg} / \mathrm{m}^{2}$, wealth tertile 3

Age 27, BMI $31.2 \mathrm{~kg} / \mathrm{m}^{2}$, wealth tertile 3

Age 33, BMI 33.4 kg/m², wealth tertile 2

Age 30, BMI 24.9 kg/m², wealth tertile 2

Age 21, BMI $22.5 \mathrm{~kg} / \mathrm{m}^{2}$, wealth tertile 2

Age 25, BMI 22.9 kg/m², wealth tertile 1

Age 27, BMI 23.3 kg/m², wealth tertile 1

Age 30, BMI $24.9 \mathrm{~kg} / \mathrm{m}^{2}$, wealth tertile 2

Age 34, BMI $28.5 \mathrm{~kg} / \mathrm{m}^{2}$, wealth tertile 3 
Table 3. Continued

\begin{tabular}{|c|c|c|c|}
\hline $\begin{array}{l}\text { Food Choice Process } \\
\text { Model Construct }^{9}\end{array}$ & $\begin{array}{l}\text { Delhi Model } \\
\text { Construct }\end{array}$ & Quotation & $\begin{array}{c}\text { Participant } \\
\text { Characteristics }\end{array}$ \\
\hline \multirow[t]{4}{*}{ Resources } & \multirow[t]{4}{*}{ Convenience } & $\begin{array}{l}\text { I don't think about cost ever while buying. I get all } \\
\text { the things under one roof, so I buy from there. }\end{array}$ & $\begin{array}{l}\text { Age } 33, \text { BMl } 27.3 \mathrm{~kg} / \mathrm{m}^{2} \text {, } \\
\text { wealth tertile } 3\end{array}$ \\
\hline & & $\begin{array}{l}\text { We normally get [grocery items] from the local } \\
\text { vendor shop nearby our house. }\end{array}$ & $\begin{array}{l}\text { Age } 21, \text { BMI } 22.5 \mathrm{~kg} / \mathrm{m}^{2} \text {, } \\
\text { wealth tertile } 2\end{array}$ \\
\hline & & $\begin{array}{l}\text { Mainly I cook variety of things on holidays, like } \\
\text { pulses, vegetables, raita, and salad. But on } \\
\text { working days it is not possible for me to cook all } \\
\text { these things together. }\end{array}$ & $\begin{array}{l}\text { Age } 34 \text {, BMI } 31.2 \mathrm{~kg} / \mathrm{m}^{2} \text {, } \\
\text { wealth tertile } 3\end{array}$ \\
\hline & & $\begin{array}{l}\text { When he [her son] leaves for school, only then I } \\
\text { have time to have my breakfast. }\end{array}$ & $\begin{array}{l}\text { Age } 27 \text {, BMI } 31.2 \mathrm{~kg} / \mathrm{m}^{2} \text {, } \\
\text { wealth tertile } 3\end{array}$ \\
\hline \multirow[t]{2}{*}{ Food strategies } & \multirow[t]{2}{*}{ Habits } & $\begin{array}{l}\text { I prepare food in the same way daily. Chapatis } \\
\text { and vegetables are fixed for lunch and } \\
\text { breakfast. }\end{array}$ & $\begin{array}{l}\text { Age } 20, \text { BMI } 21.2 \mathrm{~kg} / \mathrm{m}^{2} \text {, } \\
\text { wealth tertile } 1\end{array}$ \\
\hline & & $\begin{array}{l}\text {... We are used to having such kinds of foods. We } \\
\text { have parathas and rotis and subzis in my diet } \\
\text { now, so we are used to it. ... These chapatis } \\
\text { and subzis, this is the routine of my life, from } \\
\text { childhood. So, I'm used to it. }\end{array}$ & $\begin{array}{l}\text { Age } 32 \text {, BMI } 25.7 \mathrm{~kg} / \mathrm{m}^{2} \text {, } \\
\text { wealth tertile } 3\end{array}$ \\
\hline
\end{tabular}

BMI indicates body mass index.

afternoon" (age 20, BMI $21.2 \mathrm{~kg} / \mathrm{m}^{2}$, wealth tertile 1). A lack of time was often cited as a reason for repeating meals: "If we don't have time, then we eat leftover food from the previous day" (age 28, BMI $23.5 \mathrm{~kg} / \mathrm{m}^{2}$, wealth tertile 2 ). The same woman noted that sometimes the demands of work made it necessary to prioritize convenience over eating a variety of foods: "Whatever I get in front of me, I cook it. We are working class; our main aim is to fill the stomach and go back to work."

\section{Habit}

There were 2 subthemes relating to habit: (1) subconscious decisions and (2) food roots. Most participants did not consciously make food choices; rather, they consumed the foods they ate because that was what they had always done. The theme of habit appeared most often in interviews when women were talking about food preparation, as supported by the following quotation: "We have fixed food preparations, therefore, we don't think much before preparing food" (age 29, BMI $19.0 \mathrm{~kg} / \mathrm{m}^{2}$, wealth tertile 3 ). Many participants mentioned that food habits from their childhood had led to persistent patterns of food choice in adulthood (Table 3 ).

\section{Pile Sorts}

One participant refused to place health in any category, so there were only 37 total responses for that driver. Food safety and health were the most influential drivers in participants' food choice; $82 \%$ and $78 \%$ of participants, respectively, placed these drivers in the always category (Table 4).

Marketing/advertisements was the least influential driver of food choice; $53 \%$ of participants reported that this never influenced their food choice and only $11 \%$ said it always drove their food choice. When probed specifically about the driver of marketing during interviews, no participant said that it influenced her. Figure 2 presents results of the pile sort activity stratified by BMI and wealth index tertile.

There was no significant association between BMI category and the degree of influence of any driver on food choice. There was a significant positive relationship between wealth index tertile and the strength of 3 drivers: health, attitudes/beliefs, and hunger $(P<.001, P=.003$, and $P=.05$, respectively) on food choice. Those in the highest wealth index tertile were more likely to say that health, attitudes/beliefs, and hunger always drove their food choice.

\section{DISCUSSION}

Consistent with the Food Choice Process Model, this study found that food choice decisions are complex and multifaceted, and that life course events are important for establishing an individual's food choice trajectory. ${ }^{9,10}$ Young adult women in Delhi rely primarily on the preferences of their families, including their husbands, children, and in-laws, when making choices about food. Cultural perceptions and habits established in childhood, convenience, and food safety and health also have a critical role in the food decision-making process. These results are especially interesting considering the context of the study: Delhi, an Indian megacity that has experienced rapid economic growth (the gross domestic product per capita in Delhi increased by nearly 13\% from 2014-2015 to 2015-2016 ${ }^{18}$ ) and where urban sprawl has taken over 60,000 hectares of agricultural land. ${ }^{19}$ 
Table 4. Results of Pile Sort Activity in Which Study Participants Sorted 12 Drivers into Categories of Always, Sometimes, or Never Influence Food Choice $(n=38)$

Influences Choice of Food

\begin{tabular}{llcl} 
Driver & Always & Sometimes & Never \\
\hline Food safety & $82(31)$ & $16(6)$ & $3(1)$ \\
\hline Health & $78(29)$ & $11(4)$ & $11(4)$ \\
Taste & $68(26)$ & $18(7)$ & $13(5)$ \\
\hline Knowledge & $66(25)$ & $21(8)$ & $13(5)$ \\
\hline Attitudes & $53(20)$ & $16(6)$ & $32(12)$ \\
\hline Time & $47(18)$ & $34(13)$ & $18(7)$ \\
Cost & $42(16)$ & $24(9)$ & $34(13)$ \\
Cooking skills & $42(16)$ & $40(15)$ & $18(7)$ \\
Packaging & $34(13)$ & $32(12)$ & $34(13)$ \\
\hline Hunger & $32(12)$ & $53(20)$ & $16(6)$ \\
Mood & $29(11)$ & $58(22)$ & $16(6)$ \\
Marketing & $11(4)$ & $37(14)$ & $53(20)$ \\
\hline
\end{tabular}

Note: Data represent the percent (number) of participants.

The results indicate that the nutrition transition is well under way in Delhi and highlight important opportunities for interventions to prevent the rising threat of NCDs such as diabetes and heart disease.

A woman's family was found to be the primary driver of her decisions relating to food procurement, preparation, and consumption. These observations for urban Delhi are consistent with the results of 1 previous study on drivers of food choice in rural Kerala, which found a strong influence of the preferences of husbands and children at each stage of food choice. ${ }^{11}$ Interestingly, this study found that in some cases, strong spousal influences led to unhealthy food decisions including eating outside food, such as pizza. Two overweight women shared that they would prefer to eat less rice or cook with less oil, but that they could not make these dietary changes because of their husbands' preferences. This is a key insight for planning future interventions for obesity prevention in this young adult population. There are several examples of this in the nutrition intervention literature, for example, a weight loss intervention among Mexican American women found that participants in the group who attended classes with their spouses and children on making changes in eating habits and exercise behavior (family group) had the greatest weight loss compared with participants attending individualbased classes with dietitians (individual group) or participants receiving printed materials on nutrition and exercise (control group). ${ }^{20}$ Involving grandmothers (eg, mother or mothers-inlaw) also led to improvements in nutritional behaviors. For example, a nutrition education intervention in Senegal found that involving grandmothers positively influenced infant feeding practices of women of reproductive age. ${ }^{21}$

Cultural perceptions and habits established in childhood emerged as substantial, if sometimes subconscious, drivers of decisions relating to both foods and beverages in this sample of young adult women in Delhi. This is consistent with the category of cultural ideals from Furst et $\mathrm{al}_{1}{ }^{10}$ which are formed and established within the context of the life course, so that standards for food choice are internalized and imprinted on people's consciousness. These influences inform and shape people's personal systems, including uncon- sciously functioning strategies that may occur in a food-related choice situation..$^{10}$ Although this may suggest that these habits will be difficult to change in the context of policies aimed at improving dietary intake, results of this study also suggest that marriage may be a critical transition point at which behavior change is possible. Adopting what Verplanken and Wood $^{22}$ called downstream-plus-contextchange interventions, educational campaigns and interventions should target men and women during the natural shift in environment and subsequent lifestyle behaviors that occurs when they marry. ${ }^{23}$ Indeed, a previous study conducted among South Asian patients in the UK found that women would be more willing to participate in clinical research if their husbands were also involved, ${ }^{24}$ and pilot studies focused on chronic diseases in Chiapas, Mexico, and on the Texas-Mexico border found that involvement of spouses and other family members in the intervention is highly valued. ${ }^{25,26}$

The role of convenience, of being able to purchase all items under 1 roof, largely influenced procurement and where families bought food items. This idea is reminiscent of the rise in general merchandise superstores in the US over the past few decades. The gradual replacement of smaller, specialty grocery stores with these superstores reflects the growing demand of American consumers to consolidate their shopping trips. ${ }^{27}$ The data suggest that this ideology of convenient, 1-stop shopping seems to have taken hold with young adult women in Delhi; many reported that they purchase all of their food items from 1 location owing to price and convenience. As more women enter the workforce in India, this convenience factor may become even more influential. However, food is an essential part of Indian culture, and the researchers hypothesize that the priority placed on family members enjoying meals together, which serves the function of socialization and bringing unity to the family, is unlikely to fade.

Food safety and health consistently emerged as deterrents to eating outside food during the in-depth interviews. This concern was reiterated and 
(A)

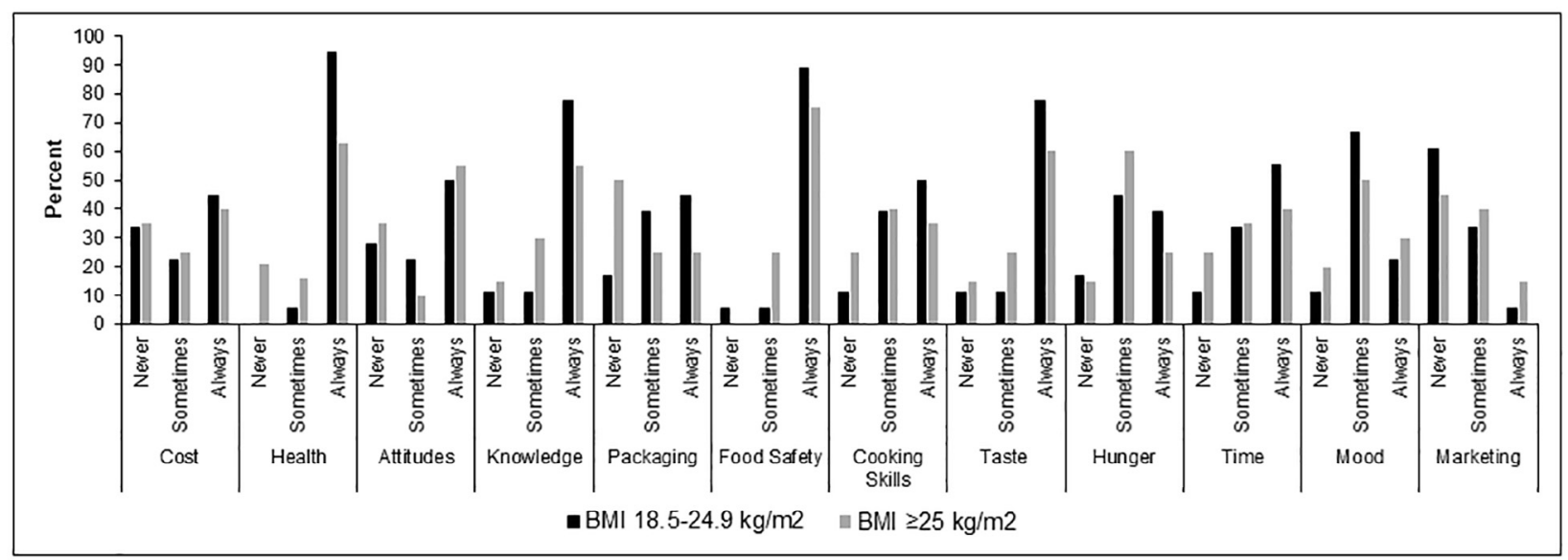

(B)

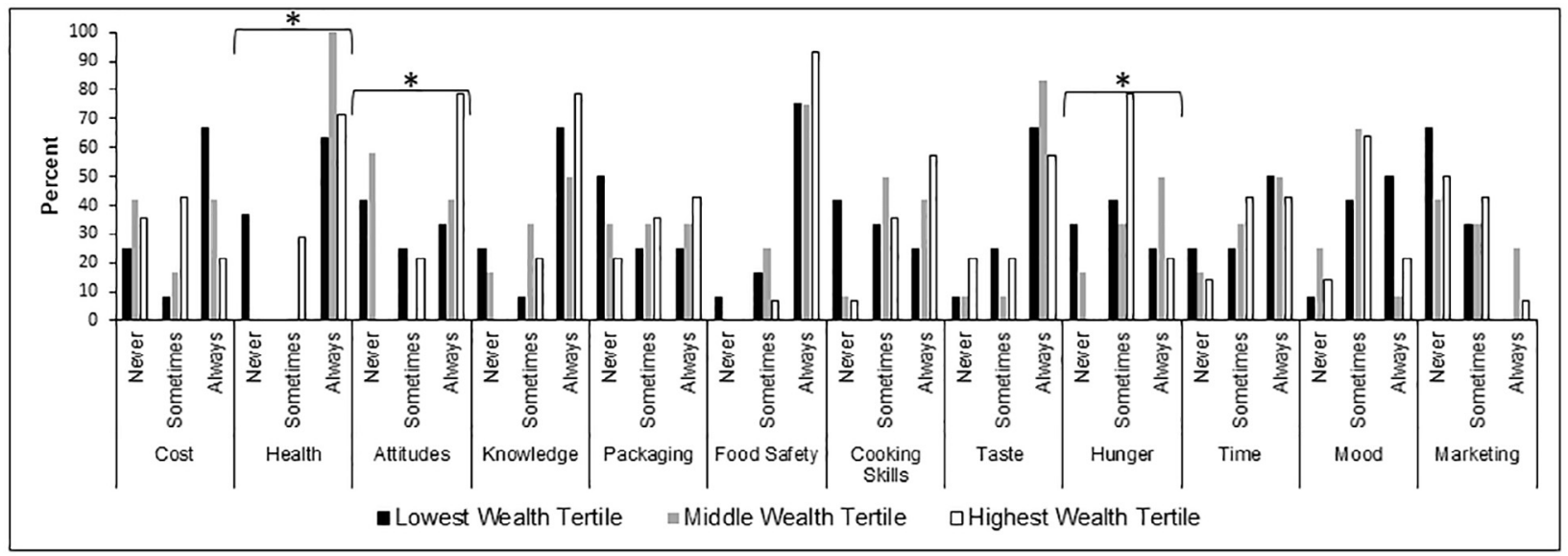

* Indicates statistical significance $(P<0.05)$

Figure 2. Pile sort activity responses graphed by (A) body mass index (BMI) category and (B) wealth index tertile. Differences in pile sort rankings (always, sometimes, or never) across tertiles of BMI and wealth index were tested using Fisher exact tests. ${ }^{*} P<.05$.

confirmed by the pile sort activity. The idea of food from Delhi being less pure than food from home villages also arose in several interviews. This may explain why such a high proportion of the Indian population fails to meet the World Health Organization's recommended intake of fruits and vegetables. ${ }^{28,29}$ Food safety is a rising concern in Delhi, where poor agricultural, manufacturing, and hygiene practices contribute to a high rate of produce contamination with pesticide residues and heavy metals. ${ }^{30}$ These concerns may contribute to inadequate vegetable and fruit consumption in this population, which has been identified as a leading risk factor for NCDs such as diabetes and heart disease. ${ }^{31}$

Food safety is 1 component of the broader concept of food security, defined by the Food and Agriculture
Organization as having "access to sufficient, safe and nutritious food that meets [an individual's] dietary needs and food preferences for an active and healthy life." 32 However, even in the poorest wealth tertile, inadequate access to sufficient food was not identified as a barrier. In several instances in this socioeconomic group, however, there were examples of women who were unable to consume foods that they preferred, such as fruits, owing to economic constraints. Thus, in addition to concerns about food safety, cost is likely a significant barrier to increasing fruit intake for some population groups.

Cost interacted with most of the primary themes, particularly with respect to convenience and procurement, when women across wealth tertiles stated that they chose a specific market because of the cheap costs.
These markets, such as Big Bazaar Outlet and Kendriya Bhandars (coops run by the Government of India, originally set up as a welfare project in 1963), ${ }^{33}$ were chosen for their dependable, high-quality products at lower prices. Some wealth-related distinctions emerged, however. For example, women in the highest wealth tertile expressed that they often did not have time to cook, which resulted in eating out or purchasing premade foods. Moreover, the concept of eating whatever was available in the house (which often meant eating the same food for consecutive meals) was common only among women in the lower and middle wealth tertiles. Interestingly, the importance of cost as a driver of food choice in the pile sort activity did not differ across wealth index tertiles. This contrasts with findings from the Kerala study, ${ }^{11}$ which found cost to be 
a primary driver, but it may reflect the fact that the Kerala study was conducted in rural areas whereas the current study was conducted in an urban area where individuals may face fewer financial barriers to obtaining food.

Nearly every participant denied the influence of television advertisements or other media on their food choices when asked in both the in-depth interview and the pile sort activity. Women named specific products such as Maggi Noodles (Nestlé) and milk supplements (eg, Bournvita [Cadbury] and Horlicks [GlaxoSmithKline]), most often related to their children's diet, which were advertised on television. Some women also mentioned that they had received pamphlets with newspapers about free home deliveries from restaurants, but they did not admit that these advertisements influenced their food choices. Studies have shown that marketing has a huge influence on food choice, especially as people move toward processed foods, but most people are unaware of their own susceptibility to the media. ${ }^{34}$ In fact, marketing works best when people are not conscious of it, because when people realize they are being marketed to, they can form a negative connection. Therefore, the uniform denial of the study participants to the influence of marketing on their food choices suggests the potential power of media to formulate a decision subconsciously and the need for innovative research to understand exposure to advertisements and the influence of marketing on food choices in this context.

The heightened awareness of health, as indicated by the pile sort activity and numerous narrative statements, may in fact be protecting young adult women in Delhi against the negative effects of the nutrition transition. Health was found to be important across all wealth categories, and indeed knowledge of nutrition, such as too much oil being unhealthy, was found in the lowest and highest wealth tertiles. Nonetheless, the cultural perceptions that homemade food is universally healthy and outside food is universally unhealthy and that junk foods are Western food but do not include processed packaged foods, are pervasive in this population. Similarly, 1 previous study conducted among 20- to 27year-old college students in Delhi also found a strong preference for homemade food over outside food. ${ }^{35}$ In addition, in this sample, no woman explicitly mentioned high-sugar or high-salt foods as being unhealthy; the focus was always on oil. These represent opportunities to improve nutrition knowledge and the healthfulness of Indian diets.

This study had several strengths. First, it was 1 of the first studies to examine drivers of food choice qualitatively in this setting, 1 in which the nutrition transition is still under way. Second, the use of multiple methods, as well as mixed methods, allowed the researchers to reach saturation and examine patterns, or their lack, across wealth tertiles and BMI categories. Incorporating the quantitative pile sorting activity into the interviews allowed for a triangulation of methods that further verified the qualitative results; aside from convenience, the majority of themes and drivers were universal across the sample. Finally, coding of transcripts was confirmed by multiple investigators individually to ensure data validity and reduce bias.

A limitation of this study was the use of convenience sampling to recruit participants based on geographical proximity, which may limit the generalizability of the results to the entire Delhi area and, more broadly, to urban cities in India. Moreover, although the sample was diverse in terms of wealth index, overall the sample was well educated (43\% had at least a college degree) and predominantly Hindu (95\% of participants), which further limits generalizability more broadly to urban cities in India. Delhi is a cosmopolitan city with individuals and families from several different states in India, and each state in India has its own food culture, choices, and habits. These results therefore represent a group of women from diverse backgrounds and culture in India. Unfortunately, information was unavailable regarding the specific area from which women who had migrated to Delhi had originated. However, drivers of food choice are likely to be context-specific, hence the importance of conducting mixed-methods research including qualitative inter- views. The results are not meant to be generalizable to the entire population, but rather to inform contextspecific, targeted interventions. Another limitation relating to sampling was that these women were participating in a larger cohort study, which has the overall aim of cardiometabolic disease surveillance. Thus, there may have been social desirability bias in the responses relating to diet and health. One limitation faced by all qualitative researchers is "the unitization problem," which is the lack of clear guidelines regarding the appropriate unit of analysis for coding transcripts. ${ }^{15}$ This is important for assessing intercoder reliability and agreement. ${ }^{15}$ This study used the excerpts from CB's coded transcripts as the unit of analysis for comparison with transcripts coded by VG and DK. However, alternative approaches to unitization are possible and would lead to different percent agreement values. ${ }^{15}$ Nonetheless, clearly defined codes and the ability to reconcile discrepancies with discussion lend strength to the analysis.

\section{IMPLICATIONS FOR RESEARCH AND PRACTICE}

This mixed-methods study found that young adult women in Delhi rely primarily on the preferences of their families, including their husbands, children, and in-laws, when making choices about food. Whereas women are often considered the gatekeepers to food in the household, ${ }^{36}$ this study indicates that their choices are still largely driven by preferences of their families. Future qualitative studies on drivers of food choice might consider interviewing husbands and mothersin-law in addition to young women, for a comprehensive family perspective. Results of this study also suggest that marriage may be a critical transition point at which behavior change is possible. To date, no such interventions targeting diet-related NCD prevention among recently married couples have been implemented in India, but this study's findings together with previous research suggest this is a promising line of research. ${ }^{22-25}$ Such studies would need to take into account issues relating to female 
empowerment and autonomy. Another important consideration is that many food decisions are habits established in childhood, and therefore they may prove difficult to change via behavioral intervention. Nonetheless, the women who were interviewed put a high value on food, perhaps because most were mothers, and this is promising because they seem open to learning about and improving their diets. Interventions targeting the prevention of obesity, diabetes, and other diet-related diseases in India could focus on recently married couples, involving the extended family in small group counseling sessions, to establish healthy dietary practices grounded in traditional foods during the preconception period to promote health for current and future generations.

\section{ACKNOWLEDGMENTS}

Funding was provided by the Harvard T.H. Chan School of Public Health. The authors wish to thank the CARRS participants who volunteered their time for this study. They would also like to thank the CARRS field team for their assistance with scheduling all participant interviews and Dr Roopa Shivashankar, the CARRS project coordinator.

\section{SUPPLEMENTARY DATA}

Supplementary data related to this article can be found at https://doi.org/ 10.1016/j.jneb.2018.03.013.

\section{REFERENCES}

1. Popkin BM. Nutritional patterns and transitions. Popul Dev Rev. 1993;19:138157.

2. Misra A, Singhal N, Sivakumar B, et al. Nutrition transition in India: secular trends in dietary intake and their relationship to diet-related noncommunicable diseases. J Diabetes. 2011; 3:278-292.

3. National Council of Applied Economic Research. An Analysis of Changing Food Consumption Pattern in India. New Delhi, India: National Council of Applied Economic Research; 2014.

4. Zhai F, Wang H, Du S, et al. Prospective study on nutrition transition in China. Nutr Rev. 2009;67(suppl 1):S56S61.
5. Rivera JA, Barquera S, González-Cossío T, Olaiz G, Sepúlveda J. Nutrition transition in Mexico and in other Latin American countries. Nutr Rev. 2004; 62(pt 2):S149-S157.

6. Radhika G, Sathya RM, Ganesan A, et al. Dietary profile of urban adult population in South India in the context of chronic disease epidemiology (CURES68). Public Health Nutr. 2011;14:591598.

7. India State-level Disease Burden Initiative Collaborators. Nations within a nation: variations in epidemiological transition across the states of India, 1990-2016 in the Global Burden of Disease Study. Lancet. 2017;390:24372460.

8. Lachat C, Otchere S, Roberfroid D, et al. Diet and physical activity for the prevention of noncommunicable diseases in low-and middle-income countries: a systematic policy review. PLoS Med. 2013;10:e1001465.

9. Sobal J, Bisogni CA. Constructing food choice decisions. Ann Behav Med. 2009; 38:37-46.

10. Furst T, Connors M, Bisogni CA, Sobal J, Falk LW. Food choice: a conceptual model of the process. Appetite. 1996;26: 247-266.

11. Daivadanam M, Wahlström R, Thankappan KR, Ravindran TK. Balancing expectations amidst limitations: the dynamics of food decision-making in rural Kerala. BMC Public Health. 2015; 15:644-656.

12. Patel SA, Ali MK, Alam D, et al. Obesity and its relation with diabetes and hypertension: a cross-sectional study across 4 geographical regions. Glob Heart. 2016;11:71-79, e4.

13. Nair M, Ali MK, Ajay VS, et al. CARRS Surveillance study: design and methods to assess burdens from multiple perspectives. BMC Public Health. 2012;12:701-712.

14. Ali MK, Bhaskarapillai B, Shivashankar $\mathrm{R}$, et al. Socioeconomic status and cardiovascular risk in urban South Asia: the CARRS Study. Eur J Prev Cardiol. 2016; 23:408-419.

15. Campbell JL, Quincy C, Osserman J, Pedersen OK. Coding in-depth semistructured interviews: problems of unitization and intercoder reliability and agreement. Sociol Methods Res. 2013;42: 294-320.

16. Tolley EE, Ulin PR, Mack N, Robinson ET, Succop SM. Qualitative Methods in Public Health: A Field Guide for Applied
Research. 2nd ed. San Francisco, CA: John Wiley \& Sons; 2016.

17. Bentley ME, Tolley EE, Pequegnat W. Qualitative inquiry: an end not just a means. In: Pequegnat W, Stover E, Boyce CA, eds. How to Write a Successful Research Grant Application: A Guide for Social and Behavioral Scientists. 2nd ed. New York, NY: Springer; 2011:153172.

18. Reserve Bank of India. Handbook of Statistics on Indian Economy 2015-16. Mumbai, India: Reserve Bank of India; 2016.

19. Chadchan J, Shankar R. An analysis of urban growth trends in the posteconomic reforms period in India. Int $J$ Sustain Built Environ. 2012;1:36-49.

20. Cousins JH, Rubovits DS, Dunn JK, Reeves RS, Ramirez AG, Foreyt JP. Family versus individually oriented intervention for weight loss in Mexican American women. Public Health Rep. 1992;107:549-555.

21. Aubel J, Touré I, Diagne M. Senegalese grandmothers promote improved maternal and child nutrition practices: the guardians of tradition are not averse to change. Soc Sci Med. 2004;59:945-959.

22. Verplanken B, Wood W. Interventions to break and create consumer habits. J Public Policy Mark. 2006;25:90-103.

23. Mata J, Frank R, Hertwig R. Higher body mass index, less exercise, but healthier eating in married adults: nine representative surveys across Europe. Soc Sci Med. 2015;138:119-127.

24. Hussain-Gambles M. South Asian patients' views and experiences of clinical trial participation. Fam Pract. 2004;21: 636-642.

25. Millard AV, Graham MA, Wang X, et al. Pilot of a diabetes primary prevention program in a hard-to-reach, low-income, immigrant Hispanic population. J Immigr Minor Health. 2011;13:906-913.

26. Fort MP, Castro M, Pena L, et al. Opportunities for involving men and families in chronic disease management: a qualitative study from Chiapas, Mexico. BMC Public Health. 2015;15:1019.

27. Basker E, Klimek S, Van PH. Supersize it: the growth of retail chains and the rise of the "big-box" store. J Econ Manag Strateg. 2012;21:541-582.

28. Finzer LE, Ajay VS, Ali MK, et al. Fruit and vegetable purchasing patterns and preferences in South Delhi. Ecol Food Nutr. 2013;52:1-20.

29. Yadav K, Krishnan A. Changing patterns of diet, physical activity and obesity 
among urban, rural and slum populations in north India. Obes Rev. 2008;9: 400-408.

30. Umali-Deininger D, Sur M. Food safety in a globalizing world: opportunities and challenges for India. Agric Econ. 2007; 37:135-147.

31. Bazzano LA, Serdula MK, Liu S. Dietary intake of fruits and vegetables and risk of cardiovascular disease. Curr Atheroscler Rep. 2003;5:492-499.

32. Food and Agriculture Organization of the United Nations, United Nations
Children's Fund, World Food Program, World Health Organization. The State of Food Security and Nutrition in the World: Building Resilience for Peace and Food Security. Rome, Italy: Food and Agriculture Organization of the United Nations; 2017.

33. Kendriya Bhandar. Central Government Employees Cooperative Society, Ltd. http://kendriyabhandar.org/. Accessed March 23, 2018.

34. Wansink B. Environmental factors that increase the food intake and consump- tion volume of unknowing consumers. Annu Rev Nutr. 2004;24:455-479.

35. Goyal A, Singh N. Consumer perception about fast food in India: an exploratory study. Br Food J. 2007;109: 182-195.

36. Khare R. Women's role in domestic food acquisition and food use in India: a case study of low-income urban households. Food Nutr Bull. 1984;6:69-76.

\section{JNEB's 2018 Best Article Award}

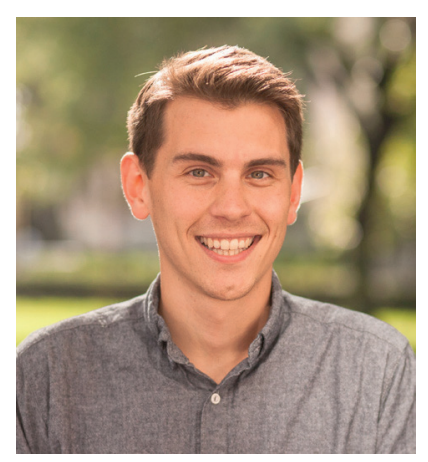

Matthew M. Graziose
Matthew Graziose, Pamela Koch, Y. Claire Wang, Heewon Lee Gray, and Isobel R. Contento

are the recipients of the JNEB Best Article Award for their article

Cost-effectiveness of a Nutrition Education Curriculum Intervention in Elementary Schools

J Nutr Educ Behav. 2017; 49:684-691 